\title{
Semper Parata: catolicismo e bandeirantismo no
}

Brasil

Semper Parata: Catholicism and Bandeirantism in Brazil

Semper Parata: catolicismo y bandeirantismo en el Brasil

EVELYN DE ALMEIDA ORLANDOID

ALEXANDRA LIMA DA SILVA

\section{Resumo}

Neste trabalho se procura discutir a dimensão religiosa presente no bandeirantismo no Brasil a partir da análise de impressos, com destaque para o periódico Bandeirantes, criado em 1928 pela Companhia do Coração de Jesus e dirigido por Maria de Lourdes Lima Rocha. Fundada em 1919, a Federação Bandeirante ainda existe até os dias atuais. O nome bandeirantismo foi sugestão do intelectual católico Jonathas Serrano. Apesar de o princípio elementar do bandeirantismo não estar ligado a nenhuma religião ou crença, é possível aferir que o movimento no Brasil esteve fortemente entrelaçado com um discurso religioso e moral na conformação da "boa bandeirante", que deveria ser devotada e dedicada à promessa de servir a Deus e a pátria, cuja base é claramente católica.

Palavras-chave: Movimento Bandeirante. Associativismo feminino. Igreja Católica.

\footnotetext{
a Pontifícia Universidade católica do Paraná (PUCPR), Curitiba, PR, Brasil. Doutora em Educação, e-mail: evelynorlando@gmail.com

b Universidade do Estado do Rio de Janeiro (UERJ), Rio de Janeiro, RJ, Brasil. Doutora em Educação, bolsita JCNE FAPERJ e Prociencia UERJ.
} 


\section{Abstract}

This paper discusses the religious dimension present in Girl Guiding in Brazil, from the analysis of printed material, highlighting the journal Bandeirantes (Girl Guides), created in 1928 by the Heart of Jesus Company, and directed by Maria de Lourdes Lima Rocha. Founded in 1919, the Federação Bandeirante (Girl Guides Federation) still exists today. The movement name in portuguese, bandeirantismo, was a suggestion from Catholic intellectual Jonathas Serrano. Although the Girl Guides elementary principle not being linked to any religion or belief, it is possible to verify that the movement in Brazil was strongly intertwined with a religious and moral discourse in the conformation of the "good girl guide", which should be devoted and dedicated to the promise of serve God and the homeland, of which basis is clearly Catholic.

Keywords: Girl Guiding, Girl Guides Movement. Female associationism. Catholic church.

\section{Resumen}

Este artículo tiene como objetivo discutir la dimensión religiosa presente en el bandeirantismo en Brasil a partir del análisis de impresos, especialmente el periódico Bandeirantes, creado en 1928 por la Compañía del Corazón de Jesús y dirigido por María de Lourdes Lima Rocha. Fundada en 1919, la Federación Bandeirante todavía existe hoy. El nombre bandeirantismo há sido uma sugerencia del intelectual católico Jonathas Serrano. Aunque el principio elemental del bandeirantismo no está vinculado a ninguna religión o creencia, es posible verificar que el movimiento en Brasil esté fuertemente entrelazado con un discurso religioso y moral en la conformación del "buen bandeirante", que debe ser dedicado y dedicado a la promesa de servir a Dios y a la patria, cuya base es claramente católica.

Palabras clave: Movimiento bandeirante. Asociacionismo femenino. Iglesia Católica.

\section{Introdução}

O Girl Guides foi um movimento fundado na Inglaterra em 1910, idealizado por Baden-Powell ${ }^{1}$, cujo objetivo era a formação completa das jovens. A difusão do

\footnotetext{
${ }^{1}$ Robert Stephenson Smith Baden-Powell nasceu na Inglaterra em 22 de fevereiro de 1857. Foi militar e o criador do escotismo. Fez uso da palavra e das viagens para difundir o escotismo pelo mundo. Autor de vários livros, dentre os quais Scouting for boys (1908), traduzido como Escotismo para Rapazes (1975) e Aids to scouting (1091), traduzido como Guia do Chefe Escoteiro (1982). No âmbito dos estudos no campo da história da educação, a respeito de Baden-Powell, merece especial atenção o livro $A$ escola de Baden-Powell: cultura escoteira, associação voluntária e escotismo de estado no Brasil, de autoria de Jorge Carvalho do Nascimento (2008).
} 
bandeirantismo pelo mundo ocorreu devido à atuação de Agnes Powell ${ }^{2}$ e de Lady Powell ${ }^{3}$, irmã e esposa de Baden-Powell, respectivamente. Graças ao interesse de Lady Powell, o movimento ganhou dimensões internacionais, pois, "O seu entusiasmo pela nobre causa foi imediatamente reconhecido pelas bandeirantes de todo os países. A sua preocupação em desenvolver o sistema educacional criado por seu esposo era sempre constante" (CORREIO DA MANHÃ, 1959, p. 2).

O bandeirantismo deu os primeiros passos no Brasil em 1919. O nome do movimento no Brasil foi dado pelo professor Jonathas Serrano ${ }^{4}$, pois considerava que "bem se aplicava a jovens que vão em busca das riquezas da alma e da alegria pura" (CORREIO DA MANHÃ, 1957, p. 16). A vertente brasileira do movimento se organizou com a criação da Federação das Bandeirantes:

Aos 13 de agosto de 1919 nasceu no Brasil a Federação das Bandeirantes, sociedade civil que tem por fim formar a mulher para a família e a Pátria, fortalecida na fé cristã. A organização das Bandeirantes é feita sob a orientação da Federação e de acordo com os métodos de Baden Powell. É constituída por um Conselho Central, que elege um Conselho Executivo, pelas Chefes de Região e de Distrito e pelas companhias de Bandeirantes, Guias, Fadinhas e alcateias de Lobinhos. Podem ser membros da Federação as pessoas que se interessarem pelo movimento, aceitando sem restrição a Promessa e o Código e seguindo as regras e diretrizes da mesma Federação [...]. O lema das Bandeirantes é SEMPER PARATA, o que significa estar ela sempre pronta para cumprir os seus deveres e servir a Deus, a Pátria e ao próximo (BANDEIRANTES, 1933, p. 48).

Há inúmeros trabalhos sobre Girl Guides no exterior, com destaque para os publicados em língua inglesa (HAMPTON, 2011; CHRISTIAN, 1947). No Brasil, alguns trabalhos foram localizados em diferentes áreas. Na área de Antropologia, a dissertação de mestrado de Maria Inez Motta (1988) explorou o lugar da mulher no movimento bandeirante no Brasil. $\mathrm{Na}$ área de Ciências Sociais, Samara dos Santos Carvalho $(2013,2014)$ analisou o debate sobre a emancipação da mulher no interior

\footnotetext{
${ }^{2}$ Agnes Smyth Powell, irmã de Baden-Powell, o ajudou na fundação do movimento Girl Guide desde 1909 na Inglaterra. Era ela quem revia seus livros e falava às jovens mulheres, tendo sido escolhida a $1^{\text {a }}$ Presidente da Associação no Reino Unido (RODRIGUES, 2016).

${ }^{3}$ Nascida Olave St. Clair Soames, em 22 de fevereiro de 1889, Dorset, Inglaterra. Aos 23 anos casou-se com o então general Robert Baden-Powell, passando a ser conhecida como Lady Baden-Powell. Desde então passou a se interessar pelo sistema educacional criado por seu marido.

${ }^{4}$ Jonathas Serrano (1885-1944) foi um educador católico, professor de História e autor de livros diversos, dentre os quais: A montanha de Cristo, 1931.
} 
da Federação das Bandeirantes, e as relações de gênero no movimento bandeirante. $\mathrm{Na}$ área de Educação Física, Herold Júnior e Vaz (2012) estudaram as representações sobre o corpo e a educação da mulher na expansão do escotismo e do bandeirantismo nas primeiras décadas do século XX. Há, ainda, a pesquisa histórica realizada por Lúcia Maria Santos Rodrigues (2016), na qual aborda os 100 anos do movimento como uma luta social e de gênero.

No campo da história da educação, especificamente, localizamos poucos trabalhos. A partir da análise da coluna "As Bandeirantes", no Correio da Manhã, Silva (2017) explora as relações entre catolicismo e bandeirantismo no Brasil, com destaque para a atuação de mulheres católicas. Por seu turno, Brito e Silva (2018) analisam as correspondências enviadas à Revista Bandeirantes - publicação oficial da Confederação das Bandeirantes do Brasil - com o objetivo de indicar as múltiplas vozes femininas, com suas angústias, aspirações e perspectivas. Já a análise das contradições presentes no processo de reformulação institucional do bandeirantismo no Brasil foi o foco do estudo de Fellini (2017).

\section{O Movimento Bandeirante entre tensões e contradições: a reformulação institucional de 1968}

O Movimento Bandeirante pode ser entendido como um tipo de associativismo feminino que, no Brasil, funcionou, no início do século XX, como tática empreendida pelas mulheres de $\operatorname{elite}^{5}$ que visavam maior emancipação feminina e o direito ao espaço público. Tais práticas associativistas, tradicionalmente analisadas na historiografia educacional relacionadas ao âmbito da docência, extrapolaram esses limites e se estenderam para frentes como a caridade, a filantropia, as letras, o feminismo e o próprio bandeirantismo. A partir desses lugares essas mulheres produziram discursos, empreenderam práticas educativas e lutaram de modos distintos contra um modelo social e cultural que as colocavam nos bastidores da história. Suas ações, ainda que, em larga medida, possam ser associadas a um conservadorismo político e social, dão a ver modos pelos quais afirmaram seu direito de existir como sujeitos, como mulheres.

\footnotetext{
${ }^{5} \mathrm{O}$ conceito de elite está sendo utilizado neste trabalho na perspectiva de Sirinelli (1998). 
Segundo Ana Paula Vosne Martins (2016, p. 3),

Foi em grande parte por meio destas associações e instituições que as mulheres brasileiras passaram a sair dos limites da vida privada e a se envolver com assuntos como orçamentos, subvenções, arrecadação de fundos, prestação de serviços de assistência, estatutos, regimentos e também a negociação com pessoas de seu círculo de relações para conseguir apoio para as atividades de benemerência. Sabe-se pouco sobre esse processo. Paira sobre estas atividades uma sombra de silêncio e esquecimento, apesar da importância do trabalho desenvolvido pelas instituições assistenciais numa época de escassez ou mesmo ausência de assistência pública.

Entretanto, as práticas associativas femininas no Brasil não se restringiram à assistência social, embora representassem a maioria. Outras associações e instituições também foram criadas desde a segunda metade do século XIX, com finalidades diversas, como associações devocionais, o apoio e a participação na campanha abolicionista, 0 incentivo à educação feminina, $O$ apoio às jovens trabalhadoras e também as associações que defendiam o direito ao sufrágio feminino e a pauta social e política do feminismo. Com exceção do feminismo, tema bastante estudado e conhecido pela história das mulheres no Brasil, as outras experiências associativas permanecem naquela mesma zona de silêncio e esquecimento das associações assistenciais.

Da ampla produção historiográfica que tem se desenvolvido sobre as mulheres na historiografia brasileira desde meados dos anos de 1980, há uma lacuna em relação às mulheres de elite, "a não ser quando participaram ativamente de movimentos feministas ou tiveram uma atuação de resistência no campo político e social, constituindo-se quase como uma voz isolada, considerada muitas vezes à frente de seu tempo" (SOIHET, 2013).

O bandeirantismo foi um movimento criado por mulheres de elite, de cunho social e pedagógico, que se constituiu ao longo do tempo como

Uma história criada por mulheres, jovens e meninas que vivenciaram diferentes épocas e avançaram em direitos políticos e sociais, em valores e costumes culturais, em ver duas guerras mundiais, as crises econômicas com as duras e conhecidas ditaduras de seus governos e em diferentes anos, em feminismos diversos e em conhecimentos acelerados em um único século, o XX, em diversas áreas humanas. (RODRIGUES, 2016, p. 1).

Pensar nas práticas educativas que ali se desenrolaram significa atentar para uma problemática histórico-educacional voltada à compreensão dos modelos pedagógicos e culturais sob os quais diferentes gerações foram educadas no Brasil. Também atentar para um conjunto de hábitos, comportamentos e valores que nortearam a educação de meninas e moças brasileiras. Por meio desse movimento 
associativista, mulheres foram mobilizadas a exercer um papel político e social de intervenção na sociedade.

\section{Nos rastros de um impresso: Bandeirantes}

Entendemos o bandeirantismo como um tipo de movimento associativista que funcionou como um dos caminhos possíveis para a constituição de grupos de intelectuais. Todo movimento associativista fomenta a construção de redes de sociabilidade. No caso dos intelectuais, segundo Sirinelli (1996, p. 254-255), eles se organizam "em torno de uma sensibilidade ideológica ou cultural comum e de afinidades mais difusas, mas igualmente determinantes, que fundam uma vontade e um gosto de conviver". Dentre as estruturas de sociabilidade intelectual, Sirinelli (1996) destaca as revistas como um suporte que confere uma estrutura ao campo intelectual por meio de forças antagônicas de adesão (amizades, fidelidades arrebanhadas) e de exclusão (visões, rupturas). A organização em torno de uma revista, segundo Sirinelli (2013), dá a ver alguns dos modos segundo os quais os intelectuais se congregam e funciona como o retrato de um grupo que quase sempre provém de um mesmo meio social, mas que ainda assim podem vir a ter itinerários distintos e a construírem destinos diferentes. As revistas são consideradas, portanto, segundo Sirinelli (1996), como um lugar de movimento de ideias e fermentação intelectual de determinado grupo.

$\mathrm{Na}$ historiografia educacional as revistas vêm sendo estudadas como instrumento pedagógico devido a seus usos e suas finalidades formativas, mesmo aquelas que não se enquadravam no escopo da educação e do ensino designadamente ${ }^{6}$. Segundo Orlando (2013), livros, revistas, jornais, opúsculos, folhetos e almanaques constituem tipos de impressos que foram usados com finalidades educativas variadas. Essa pluralidade sinaliza para um importante caminho de investigação da história dos impressos que é a "circulação, em larga escala e para numerosas utilizações, do texto escrito multiplicado pela prensa tipográfica" (CHARTIER, 1998, p. 21).

\footnotetext{
6 Sobre esse tema, ver: Machado Júnior (2006), Orlando (2013), Martins (2001), Freire (2006), Bassanezi (1996), Bicalho (1988), Sgarbi $(2001,1997)$, dentre outros.
} 
$\mathrm{Na}$ perspectiva do movimento eles tiveram um caráter informativo e formativo, seguindo a mesma linha pedagógica do movimento escoteiro, tal como o analisou Nascimento (2008, p. 171):

\begin{abstract}
Os impressos que trataram do movimento escoteiro tiveram caráter formativo, instrutivo e regulador da vida social, sobretudo nos aspectos morais, além de serem ferramentas para a formação do homem civilizado [...] A ideia de moralidade era parte importante da cultura do movimento escoteiro e dizia respeito aos padrões do processo civilizador. As regras de civilidade estiveram sempre presentes nos seus impressos. Uma forma de civilidade compatível com aquilo que Norbert Elias considerava ser o homem civilizado, ou seja, aquele que era capaz de exercer o controle sobre as paixões, de rejeitar o que queria o coração, de agir contra os próprios sentimentos, de conter o prazer e a inclinação do momento pela previsão das consequências desagradáveis, caso seus impulsos fossem atendidos.
\end{abstract}

A Revista Bandeirantes, para além dessa função pedagógica que exercia, à medida que fazia circular notícias, orientações e experiências que deveriam servir como inspiração para suas leitoras, funcionou com uma finalidade política de criar uma estrutura de sociabilidade intelectual no interior do movimento. Nesse cenário um nome de destaque no bandeirantismo brasileiro foi o de Maria de Lourdes Lima Rocha ou, simplesmente, "Chefe Lourdes". Professora e pedagoga que fundou a Companhia do Sagrado Coração de Jesus, em Botafogo, além de ter sido diretora e fundadora da Revista Bandeirantes.

Lourdes Lima Rocha era a própria personificação de chefe bandeirante. Seu temperamento arrebatado as vezes provocava debates, porém com bom humor, largueza de vistas e compreensão humana, logo congregava, em torno de sua personalidade irradiante de simpatia, quem dela se aproximava (CORREIO DA MANHÃ, 1957, p. 16).

Em 1926 Lourdes Lima Rocha foi convidada pelo Padre Leovigildo Franca ${ }^{7}$ para fundar uma companhia bandeirante. A Companhia do Sagrado Coração de Jesus funcionava na própria sede da paróquia do padre, na Rua Benjamim Constant, número 42. A sede central da Federação Bandeirante Brasileira foi construída no terreno atrás da Igreja também. O apoio da Igreja Católica ao movimento, no Brasil, se fez presente em outros vários momentos:

\footnotetext{
7 O padre Leovigildo Franca era irmão do padre Leonel Franca, o que indica a influente assessoria religiosa que o movimento recebeu desde o seu início.
} 
Em março de 1927, o Cardeal Arcebispo do Rio de Janeiro, D. Sebastião Leme abençoa as Bandeirantes. Em maio do mesmo ano a Companhia do Sagrado Coração de Jesus inicia a publicação de um pequeno jornal, denominado Bandeirantes, o mesmo que a partir de 1931 é órgão oficial da F.B.B. (CORREIO DA MANHÃ, 1957, p. 16).

Embora os fatos sobre esse início sejam pouco precisos, o que se sabe é que o periódico Bandeirantes nasceu como jornal, criado pela chefa Lourdes, no Sagrado, como um periódico local (SILVA, 2016, p. 2017). Depois foi considerado órgão da Federação das Bandeirantes do Brasil e, posteriormente, transformado na revista nacional do movimento (RODRIGUES, 2016). ${ }^{8}$

Por essa razão, os primeiros exemplares do impresso de propaganda dos valores do movimento, ora se apresentava como jornal, ora como revista. Apresentava periodicidade mensal, fundado pela Companhia do Coração de Jesus, com redação e administração na Rua Benjamin Constant, 42. O exemplar avulso era vendido por $1 \$ 000$ em 1933, também poderia ser adquirido por assinaturas simples, proteção e honra.

Além de relatórios, mensagens das lideranças, conselhos, atividades lúdicas, correspondências, o impresso contava com artigos de personalidades consideradas importantes para a causa. O número referente a maio de 1933 trazia a tese de Gilda Rocha Miranda lida no Congresso Eucarístico de Santana. A chefa bandeirante defendia que a juventude católica deveria resistir às paixões e seguir o caminho das virtudes: "Sejamos puros! Sejamos apóstolos! Sejamos santos! Para que, por nós, o Cristo viva, o Cristo reine, o Cristo impere sobre a humanidade" (MIRANDA, 1933c, p. 3).

\title{
A promessa da bandeirante: Deus, pátria e lar
}

\author{
É a seguinte a promessa que faz a menina ao \\ ingressar no movimento: \\ Prometo sob minha palavra de honra, ser leal a Deus e \\ a minha Pátria, ajudar o próximo em todas as \\ ocasiões, obedecer ao código das bandeirantes \\ (REVISTA BANDEIRANTES, 1946, p. 1).
}

\footnotetext{
${ }^{8}$ A dispersão dos impressos é bastante grande. Na Biblioteca Nacional foi encontrado apenas o exemplar de 1928. Mas nos arquivos da Federação das Bandeirantes do Brasil há todos os números disponíveis para pesquisa. Todavia, os exemplares analisados no presente artigo foram os dos anos de 1933, 1944, 1945, primeiros exemplares aos quais tivemos acesso na pesquisa, localizados e adquiridos em sebos da cidade do Rio de Janeiro.
} 
Fazer a promessa em frente à bandeira que carrega o símbolo do bandeirantismo é parte do ritual de iniciação da bandeirante. Tal promessa deveria ser honrada mediante o cumprimento de um código, o qual estabelecia que "o sentimento da bandeirante é sagrado e sua palavra merece toda a confiança” (REVISTA BANDEIRANTES, 1946, p. 1). A bandeirante deveria obedecer a ordens e hierarquia, sendo leal a Deus e à pátria em primeira instância.

Figura 1 - Ilustração Inspirada no Lema "Servir a Deus, a Pátria e a Federação"

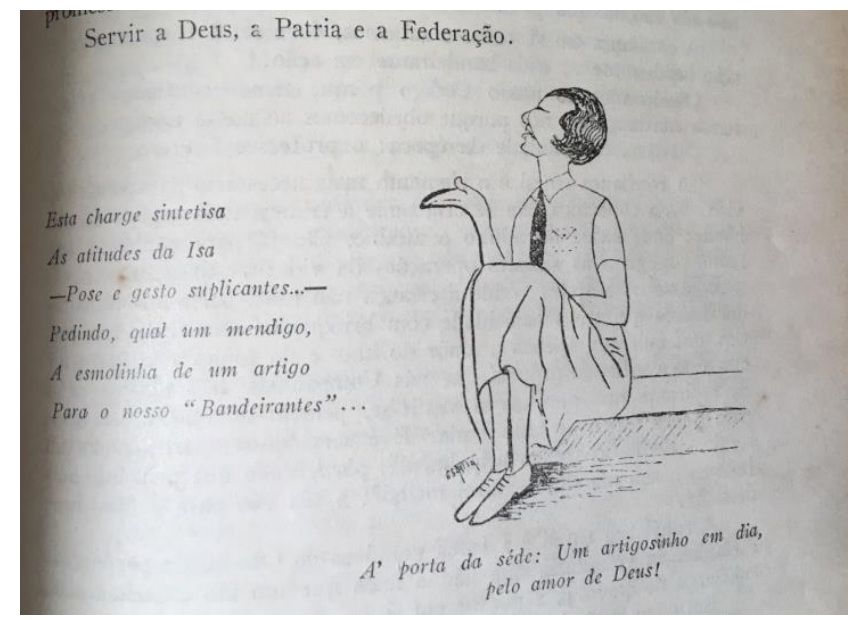

Fonte: Revista Bandeirantes (1933b, p. 21).

Em artigo intitulado "O movimento bandeirante, sua organização e propaganda no Brasil", Rosita Sampaio Bahiana (BANDEIRANTES, outubro, 1933, p. 46) defendia que:

Sendo o Brasil um país essencialmente católico, a religião da Bandeirante é a Católica, Apostólica Romana, o que não impede que sejam admitidas meninas de outras crenças. A F.B.B. faz parte da 11 comissão (Juventude Feminina Católica) da Confederação Católica do Rio de Janeiro. 'A religião é essencial a felicidade', diz Baden Powell, e a bandeirante deve cultivar com energia e sinceridade a sua fé, respeitando sempre os outros credos de suas irmãs. Entre os males que afligem a sociedade moderna o grande Chefe Escoteiro coloca em primeiro lugar a irreligião, e para combatê-lo, recomenda a prática leal e constante de uma fé esclarecida e forte.

Outro objetivo do movimento bandeirante era a formação para o lar, ou seja, "fazer das jovens de hoje perfeitas mães de família de amanhã" (BANDEIRANTES, outubro, 1933, p. 46). Portanto, a família seria o principal alicerce na formação da individualidade: 
O lar deve pois centralizar todo o nosso poder de ação e daí então ser irradiada sua força e benfazeja em proveito de outrem. Mesmo porque, como poderia uma bandeirante cumprir conscienciosamente seu dever de ajudar ao próximo se aos mais próximos a ela não auxiliar primeiro? A confiança em si, como sabemos, deve ser a força motriz da ação bandeirante... e da bandeirante em ação (BANDEIRANTES, 1933a, p. 22).

Obediência é uma característica primordial na conduta da boa bandeirante. Obedecer é fundamental para aprender e se deixar ser educada. E com ternura e otimismo, pois nas palavras de Baden-Powell, "Deus não criou os movimentos bruscos. Não se faz, pois, uma dona de casa e mãe de família apenas com o conjugo vobis. Muitas se fazem a custa de paciência, do bolso do marido e da saúde do primeiro filho, muitas vezes sacrificada pela sua inexperiência” (BANDEIRANTES, 1933a, p. 23).

A boa bandeirante deveria ser exemplar, abnegada e altruísta, pois deveria praticar a caridade e boas ações:

Uma católica fervorosa, uma brasileira que ame seu povo não pode ficar se divertindo enquanto há crianças que vivem sem fé e sem alegria. Se assim procedêssemos negaríamos a educação que nossas famílias nos deram. Mas se cremos que o Bandeirantismo é necessário, é preciso praticá-lo com entusiasmo; levar a ele nossos pais, irmãos, toda a nossa família. Tenhamos fé no que estamos fazendo e a vitória será nossa! (BANDEIRANTES, 1933d, p. 28).

Além da obediência a Deus, a promessa também incluía a prática da caridade cristã, pois conforme o código, “a Bandeirante ajuda o próximo em todas as ocasiões". Na edição de junho de 1945, o artigo intitulado "Copacabana sobe o morro" dá visibilidade às ações da chefa Ginete no morro do Cantagalo, conferindo grande destaque ao que consideravam coragem e dedicação da chefe, pois "É realmente um grande esforço para uma chefe subir o morro 2 vezes por semana para dar reuniões e instrução"(BANDEIRANTES, 1945b, p. 159).

Todavia, a ação "bem-intencionada" dessas bandeirantes - marcada muito fortemente pelo lugar social que ocupavam como mulheres de elite em larga medida e por uma cultura basicamente racista - não estava isenta de um olhar preconceituoso em relação aos meninos negros e pobres:

Dizer que vimos crianças doentes, malnutridas e abandonadas, casebres miseráveis e falta de higiene, seria ficar na mesma. Mas vimos também a companhia de chefe Ginette: 20 garotos pretinhos e reluzentes em seus uniformes brancos, todos muito cortezes recebendo as bandeirantes lá de baixo (BANDEIRANTES, 1945b, p. 159). 
Figura 2 - O Bandeirantismo no Morro

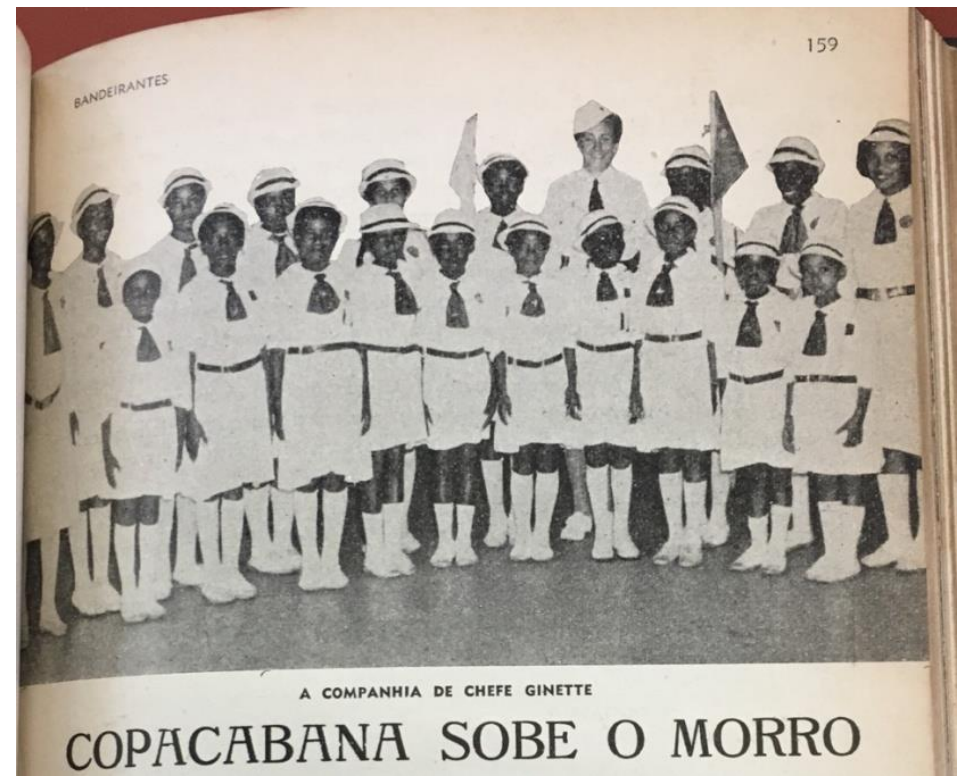

Fonte: Revista Bandeirantes (1945b, p. 159)

O protagonismo da ação é sempre da abnegada chefa que tinha como missão o sacrifício de "civilizar" os meninos "pobres, negros e favelados", numa árdua tarefa, uma vez que

[...] é mais difícil ainda ensinar aquela criançada a ser limpa, e comer bem, a ser cortez e a ajudar o próximo. Mas a chefe Ginette tem conseguido tudo isso. É um exemplo de dedicação para todas as companhias que existem e existirão por estes morros aí pelo Brasil agora (BANDEIRANTES, 1945b, p. 159).

Figura 3 - Diversidade Étnica e de Classe Social no Movimento

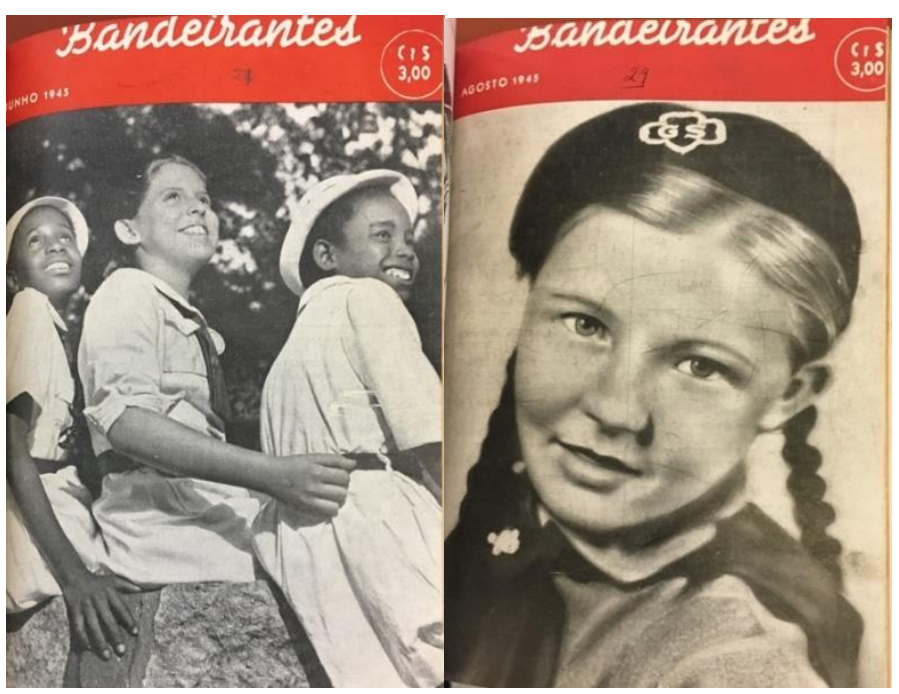

Fonte: Capas da Revista Bandeirantes (1945b, p. 1) 
Não obstante haver uma ênfase permanente na boa ação, esta não deveria ser demasiadamente ostensiva, para não acomodar os sujeitos na preguiça e nos vícios. O caminho para a salvação dos meninos pobres seria pela educação e pelo próprio esforço:

As bandeirantes sabem que não adianta dar roupa e comida, mas sim ensinar a fazer roupa e comida e proporcionar os meios para isso. Fazer a educação vir de dentro do próprio ambiente. Não alimentar a preguiça com caridade ostensiva. $\mathrm{O}$ bandeirantismo pode fazer um grande bem a classe pobre. A bandeirante que possui meios sente que deve ajudar sua irmã do morro e da fábrica a ter também as oportunidades que ela teve. Vestem todas o mesmo uniforme, têm o mesmo ideal (BANDEIRANTES, 1945b, p. 159).

A promessa e a missão de servir, características basilares do movimento, não ficaram incólumes às políticas do seu tempo e a alguns dos discursos médicos higienistas, chegaram mesmo a criar companhias separadas para meninas pobres ou e outra religião, como as judias. Um erro, segundo Rodrigues (2016), que só foi reparado por volta de 1960.

\section{Moral católica e identidade social}

Segundo Rodrigues (2016), a fundação do Movimento Bandeirante no Brasil encontrou fortes críticas da sociedade que o via de forma pejorativa, associando-a à educação inglesa e masculinizada. Não faltaram manifestações na imprensa rechaçando o movimento. Todavia, a força do associativismo era estratégica: "Isso facilitou a construção de uma identidade de gênero com a nova segurança grupal" (RODRIGUES, 2016, p. 65). O endosso da Igreja foi determinante nesse processo e a presença do padre Leovigildo Franca, como orientador espiritual, contribuiu para legitimar o movimento junto a alguns setores mais conservadores, funcionando quase como uma garantia de que o movimento não representava uma ameaça às balizas morais da sociedade e das famílias.

Essa desmistificação do papel feminino e sua possibilidade no MB vai ficar muito clara quando recebem ajuda do padre Leovigildo Franca em 1926, que afirmou a respeito do $\mathrm{MB}$ "ser esse um bom caminho de liberdade para a mulher, para que forme desde jovenzinha um caráter mais adequado, novo e moderno em seus direitos e possa se estender para outras meninas e moças" [...] E ele era um escoteiro (RODRIGUES, 2016, p. $67)$. 
Na sequência da tese de Gilda Rocha Miranda, a Revista Bandeirantes divulga o resumo da conferência do Padre Leonel Franca S. J, realizada no Externato do Sacré Couer, em 20 de abril de 1933, intitulada Ação Católica e Educação. Defendia o padre que:

A juventude é a natureza humana na melhor de suas energias, não é portanto de admirar que em torno da escola se travem as mais renhidas batalhas. Todo movimento social que deseja não morrer vai bater a porta das escolas. E se em nossos dias tanto se luta no campo da Pedagogia, é porque nos achamos em face de uma grande crise de civilização. Ora, nesta grande agitação moderna de ideias e de princípios, não nos é permitido, a nós, católicos, cruzar os braços, queixarmos-nos do passado, lamentar o presente e desesperarmos-no do futuro (BANDEIRANTES, 1933c, p. 18)

As comemorações do aniversário de 14 anos da F. B. B. também ocuparam as páginas da Revista Bandeirantes. As palavras do Padre Leovigildo Franca após a missa em ação de graças, mereceram especial destaque:

Quando a maioria dos membros da nossa Federação - Chefes e Bandeirantes - se convencer desta verdade e se dedicar com afan a este trabalho pessoal de aperfeiçoamento e de santidade, pelo cumprimento integral dos três artigos de sua promessa, e na fornalha das virtudes cristãs forjar a tempera de aço de um verdadeiro caráter, então a F. B. B pode marchar serena para a conquista da mocidade certa de colher os louros da vitória [...]. A bandeirante que se eleva, eleva o Brasil (BANDEIRANTES, agosto/setembro, 1933, p. 3).

Em função das comemorações pelo aniversário de 14 anos da Federação, foi elaborado o estudo "A confederação Católica e o Bandeirantismo”, cujas conclusões foram divulgadas na revista:

1-Fazer o pedido ao Sr. Cardial para a F.B.B fazer parte da Confederação Católica; 2- Que as chefes não descurem sua cultura bandeirante. A falta de cultura específica nas dirigentes e organizadoras importa no insucesso do movimento (BANDEIRANTES, agosto/setembro, 1933, p. 9).

A presença da Igreja junto ao movimento atribuiu um caráter de missão social às Bandeirantes. Sua identidade social era forjada com base no serviço ao próximo, no sentido de irmandade, no respeito às hierarquias, no trabalho pelo bem comum e na lealdade a Deus e à Pátria, conforme a Promessa de entrada no movimento. 


\section{Considerações finais}

Semper parata! A partir deste código de conduta moral e ritos o movimento bandeirante procurava educar meninas e moças para serem e permanecerem bandeirantes. O impresso Bandeirantes era parte do projeto de expansão do bandeirantismo no Brasil, pois garantia a circulação das ideias e valores do movimento de norte a sul do país.

A Revista Bandeirantes, analisada neste artigo em seus anos iniciais, evidencia a amálgama que existia no Brasil entre o movimento e a Igreja católica, apesar do seu fundador lorde Baden-Powell enfatizar que o Movimento Bandeirante não era de natureza religiosa e não deveria fazer nenhum tipo de distinção de credo, raça ou classe social. Ainda assim, o que vemos veiculado nas páginas da revista são lições de moral católica balizando a pedagogia bandeirante desde a sua fundação, enraizando-se em suas bases e servindo como bússola para todas as jovens que procuravam no movimento forjar uma identidade social.

O envolvimento de lideranças católicas endossando o movimento deu a ele, no Brasil, marcas singulares em relação a outros países. Inicialmente, de matriz anglicana, na sociedade brasileira, a força da cultura católica se fez presente, não deixando escapar a potência pedagógica do movimento e associando-a ao debate corrente sobre emancipação feminina, o qual ganhava fôlego entre os/as intelectuais brasileiros/as e tinha, como único ponto de consenso, a educação.

É plausível a defesa de que a atuação da "Chefe Lourdes" foi crucial para a forte marca católica do bandeirantismo no Brasil, diferente de outras vertentes, como a anglicana, por exemplo. Lourdes Lima Rocha era católica e foi uma das fundadoras da Companhia do Sagrado Coração de Jesus no Rio de Janeiro, local onde nasceu o periódico Bandeirantes. Para além dela, destacam-se também outras mulheres, como Jeronyma Mesquita, forte liderança católica que participou ativamente de diferentes associações femininas, inclusive na Federação Brasileira pelo Progresso Feminino, o que indica alguns dos modos pelos quais a Igreja participou desse debate e elaborou um conjunto de práticas em diálogo com o que havia de mais moderno no campo da educação. 
O Movimento Bandeirante também é uma forte expressão do associativismo feminino, tática mobilizada por algumas intelectuais católicas que legitimava sua circulação no espaço público. A educação, a cultura e a assistência foram, em princípio, os âmbitos em que elas mais se envolveram, exercendo politicamente, a partir dessas frentes, um conjunto de ações voltadas a assegurar as bases católicas da sociedade brasileira.

\section{Referências}

BASSANEZI, C. Virando as páginas, revendo as mulheres: revistas femininas e relações homemmulher, 1945-1964. Rio de Janeiro: Civilização Brasileira, 1996.

BICALHO, M. F. B. O bello sexo: a imprensa, identidade feminina no Rio de Janeiro em fins do século XIX e início do século XX. 1988. 268 f. Dissertação (Mestrado em Antropologia Social) - Programa de Pós-Graduação em Antropologia Social do Museu Nacional, Universidade Federal do Rio de Janeiro, UFRJ, Rio de Janeiro, 1988.

BRITO, D.; SILVA, A. L. da. Em correspondência: vozes femininas na revista Bandeirantes. In: Ana Chrystina Mignot (org.). A ilusão do leitor: cartas, imprensa e educação. v. 1. Curitiba: CRV, 2018. p. 121-142.

CARVALHO, S. S. A Federação das Bandeirantes no limiar dos anos sessenta: uma proposta de emancipação da mulher? 2013. 84 f. Trabalho de Conclusão de Curso (Graduação em Ciências Sociais) - Faculdade de Filosofia e Ciências, Universidade Estadual Paulista, Unesp, Marília, 2013.

CARVALHO, S. S. O Movimento Bandeirante e as relações de gênero no contexto social brasileiro do século XX. 2014. Dissertação (Mestrado em Ciências Sociais) - Faculdade de Filosofia e Ciências, Universidade Estadual Paulista, Unesp, 2014.

CHARTIER, R. A aventura do livro: do leitor ao navegador. Tradução de Reginaldo de Moraes, São Paulo: Unesp: Imprensa Oficial do Estado, 1998.

CHRISTIAN, C. The big test: the story of the girl guides in the World War. [S.1: Girl Guides Association, 1947.

FELLINI, M. O movimento bandeirante entre tensões e contradições: a reformulação institucional de 1968. 2017. Dissertação (Mestrado em Educação) - Universidade do Vale do Rio dos Sinos, Univale, São Lepoldo, 2017.

FREIRE, M. M. L. Mulheres, mães e médicos: discurso maternalista em revistas femininas (Rio de Janeiro e São Paulo, década de 1920). 2006. Tese (Doutorado) - Fundação Oswaldo Cruz, Rio de Janeiro, 2006.

HAMPTON, J. How the Girl Guides Won the War. [S.d: HarperCollins Publishers, 2011. 
HEROLD JUNIOR, C.; FERNANDEZ VAZ, A. A educação corporal em Baden-Powell: o movimento escoteiro contra o intelectualismo escolar. Revista HISTEDBR On-line, Campinas, n. 47, p. 166-184, set. 2012.

MACHADO JÚNIOR, C. S. Fotografias e códigos culturais: representações da sociabilidade carioca pelas imagens da revista Careta (1919-1922). 2006. 145 f. Dissertação (Mestrado em História) - Pontifícia Universidade Católica do Rio Grande do Sul, Porto Alegre, 2006.

MARTINS, A. L. Revistas em Revista: Imprensa e Práticas Culturais em Tempos de República, São Paulo (1890-1922). São Paulo: Editora da Universidade de São Paulo: Fapesp: Imprensa Oficial do Estado, 2001.

MARTINS, A. P. V. Itinerários do associativismo feminino no Brasil: uma história do silêncio. Delaware Review of Latin American Studies, v. 17, n. 2, 14 nov. 2016.

MOTTA, M. I. F. Bandeirantismo no Brasil: um estudo de caso sobre mulher e modernidade. 1988. Dissertação (Mestrado em Antropologia Social) - Programa de Pós-Graduação em Antropologia Social do Museu Nacional, Universidade Federal do Rio de Janeiro, UFRJ, Rio de Janeiro, 1988.

NASCIMENTO, J. C. A escola de Baden-Powell: cultura escoteira, associação voluntária e escotismo de estado no Brasil. Rio de Janeiro: Imago, 2008.

ORLANDO, E. A. Educar-se para educar: o projeto pedagógico do monsenhor Álvaro Negromonte dirigido a professoras e famílias através de impressos (1936-1964). 2013. 360 f. Tese (Doutorado em Educação) - Programa de Pós-Graduação em Educação, Universidade Federal do Rio de Janeiro, UERJ, Rio de Janeiro, 2013.

RODRIGUES, L. M. S. Movimento Bandeirante no Brasil: uma Luta Social de Gênero. Rio de Janeiro: S/E, 2016.

SGARBI, A. D. Bibliotecas Pedagógicas Católicas: estratégias para construir uma civilização cristã e conformar o campo pedagógico através do impresso (1929-1938). 2001. Tese (Doutorado em Educação) - Pontifícia Universidade Católica, São Paulo, 2001.

SGARBI, A. D. Igreja, educação e modernidade na década de 30: escolanovismo católico construído na CCBE divulgado pela Revista Brasileira de Pedagogia. 1997. Dissertação (Mestrado em Educação) - Pontifícia Universidade Católica, São Paulo, 1997.

SILVA, A. L. Lado a lado: marcas católicas do Bandeirantismo no Brasil. Revista História da Educação, v. 21, n. 52, maio/ago. 2017.

SIRINELLI, J.-F. Entrevista realizada por Marieta de Moraes Ferreira em Rio de Janeiro, 5 de novembro de 2012. Transcrição de Charlotte Riom. Tradução de Anne Marie Milon. Revista Brasileira de História, São Paulo, v. 33, n. 65, p. 407-412, 2013.

SIRINELLI, J.-F. As Elites Culturais. In: SIRINELLI, J.-F. Para uma História Cultural. Lisboa: Estampa, 1998. p. 259-279.

SIRINELLI, J.-F. Os intelectuais. In: RÉMOND, R. (org.). Por uma bistória política. Rio de Janeiro: UFRJ, 1996. 
SOIHET, R. Feminismos e antifeminismos: mulheres e suas lutas pela conquista da cidadania plena. Rio de Janeiro: 7 Letras, 2013.

\section{Fontes}

AS BANDEIRANTES festejam 40 anos de fundação do movimento no país. Correio da Manhã, 13/08/1959, p. 2.

ATAHYDE, M. J. Q. A. de. O bandeirantismo e sua história no Brasil. Correio da Manhã, 23/04/1957, p. 16.

BAHIANA, R. S. O movimento bandeirante, sua organização e propaganda no Brasil. Bandeirantes, out. 1933, p. 46.

MIRANDA, G. R. Congresso Eucarístico de Santana. Bandeirantes, maio 1933, p. 3.

REVISTA BANDEIRANTES, outubro, 1933g, p. 46

REVISTA BANDEIRANTES, Rio de Janeiro, 1933a. p. 23.

REVISTA BANDEIRANTES, Rio de Janeiro, abr. 1933b. p. 21.

REVISTA BANDEIRANTES, Rio de Janeiro, maio 1933c. p. 18.

REVISTA BANDEIRANTES, Rio de Janeiro, jun. 1933d. p. 28

REVISTA BANDEIRANTES, Rio de Janeiro, ago./set. 1933e. p. 3.

REVISTA BANDEIRANTES, Rio de Janeiro, ago./set. 1933f. p. 9.

REVISTA BANDEIRANTES, Rio de Janeiro, jun. 1945a. p. 159.

REVISTA BANDEIRANTES, Rio de Janeiro, jun./ago. 1945b. p. 1

REVISTA BANDEIRANTES, Epígrafe. Rio de Janeiro, 1946. p. 1. 